\title{
KOMODIFIKASI WARGA DALAM RUANG CITIZEN JOURNALISM
}

\author{
Rulli Nasrullah \\ Kajian Budaya dan Media Sekolah Pascasarjana Universitas Gadjah Mada dan Fakultas \\ Dakwah dan Komunikasi UIN Syarif Hidayatullah Jakarta \\ Email:kangarul@gmail.com \\ Irwan Abdullah dan G.R. Lono Lastoro Simatupang \\ Jurusan Antropologi Fakultas Ilmu Budaya Universitas Gadjah Mada
}

\begin{abstract}
Citizen journalism has been influenced not only by the organizational culture of media and news criteria, but also the position of citizens. Citizens have merely been considered consumers and their position passive to information produced by traditional media. With the emergence of citizen journalism, citizens now not only become news consumers but also act as news producers and consumers at the same time (produsage). The commodification of citizen journalism is a phenomenon of counter commodification done by the traditional media companies. This shows that there are symptoms of mutual attraction in the space (market) of citizen journalism, in which citizens do not always react passively to the exposure of media and become a commodity for traditional media companies or the advertisers, but also commodify in accordance with their own goals. Thus, this research is a rebutting the definition of citizen journalism popularized by Curt Chandler and Jesse Hicks from Penn State University, who said that citizen journalism is citizens activities in publishing content because of their interest in a case, without economic motives or personal gains.
\end{abstract}

Keywords: Citizen Journalism, Audience, Commodification, New Media, Self-Commodity

\begin{abstract}
ABSTRAK
Citizen journalism membawa pengaruh tidak hanya pada kultur organisasi media dan kriteria berita, tetapi juga pada posisi khalayak atau warga. Selama ini, warga merupakan konsumen dan berposisi pasif terhadap informasi yang diproduksi oleh media tradisional. Dengan kehadiran citizen journalism, warga tidak hanya mengkonsumsi, melainkan telah berperan sebagai produsen sekaligus konsumen (produsage). Komodifikasi terhadap media citizen journalism yang dilakukan oleh warga merupakan fenomena tandingan komodifikasi yang dilakukan oleh perusahaan media tradisional. Ini menunjukkan adanya gejala tarik-menarik dalam ruang (pasar) citizen journalism. Bahwa, tidak selamanya warga bersikap pasif terhadap terpaan media dan dijadikan komoditas oleh perusahaan media tradisional maupun pengiklan, melainkan warga juga bisa melakukan komodifikasi sesuai dengan capaian apa yang ingin diraih oleh mereka. Dengan demikian, penelitian ini membantah definisi tentang citizen journalism, sebagaimana dipopulerkan oleh Curt Chandler dan Jesse Hicks dari Penn State University yang menyatakan, bahwa citizen journalism merupakan aktivitas warga dalam mempublikasikan konten karena ketertarikan terhadap sebuah kasus tanpa adanya motif ekonomi atau keuntungan pribadi.
\end{abstract}

Kata Kunci: Citizen Journalism, Warga, Komodifikasi, Media Baru, Self-Commodity 


\section{PENGANTAR}

Tulisan ini merupakan upaya kritis terhadap posisi audiences (warga) di media citizen journalism (jurnalisme warga) dalam jaringan (online) dan pengaruhnya terhadap media tradisional. Mengapa hal ini perlu dikritisi? Pertama, karena di media citizen journalism online warga tidak hanya sebagai konsumen dari produksi konten seperti posisi yang selama ini terjadi di media tradisional, tetapi juga warga memposisikan diri sebagai (alat) produksi hingga mendistribusikan konten. Bahkan, dalam kondisi tertentu warga menjadi bagian dalam 'membangun' konten. Kedua, apa yang dilakukan oleh warga ketika memproduksi konten dan menyebarkannya di media citizen journalism tersebut selama ini dipahami sebagai tindakan sukarela dan tanpa dilandasi oleh motif untuk mendapatkan keuntungan pribadi seperti uang atau pengaruh atau yang disebut sebagai latarbelakang ekonomi-politik. Hal ini dipertegas oleh Curt Chandler, yang menyatakan bahwa maraknya warga yang berpartisipasi dalam melaporkan peristiwa di citizen journalism dikarenakan olah adanya ketertarikan mereka terhadap sebuah peristiwa dan juga kontribusi yang diberikan semata-mata hanya untuk menyebarkan informasi tanpa ada motif ekonomi maupun politik di baliknya.

"Citizen-journalists are regular people who contribute to news reporting, not for monetary reward, but because they have a particular interest in a topic," said Curt Chandler, senior lecturer in communications at Penn State. Chandler teaches future journalists how to adapt to a changing media environment, where the audience doesn't just read the news, but helps make it (Hicks, 2008).

Ketiga, karakteristik media baru secara langsung maupun tidak akan menjadi pesaing, jika tidak dikatakan sebagai menggerus, posisi media tradisional. Media massa seperti koran, radio, televisi, dan sebagainya tidak lagi menjadi satusatunya sumber informasi. Warga, dengan adanya fenomena citizen journalism, bisa mendapatkan informasi tersebut secara langsung dari berbagai sumber dan yang paling utama lepas dari konstruksi realitas sebagaimana yang dilakukan oleh institusi media tradisional.

Pada tataran praktis selanjutnya, warga yang terlibat di dalam media citizen journalism tidak hanya sebagai konsumen dari produk, tetapi juga sudah menjadi produsen, pengembang cum distributor. Fenomena yang berbeda jika melihat posisi warga di dalam media tradisional seperti koran, televisi, maupun radio. Konten, baik yang bersifat informasi maupun hiburan di media tradisional pada dasarnya diproduksi oleh korporasi media yang bersangkutan. Posisi warga hanya sebatas pada konsumen yang mengonsumsi produk konten yang dihasilkan. Tentu saja, dalam perspektif kritis bahwa konten yang didistribusikan di media tradisional merupakan hasil produksi pekerja industri, dalam hal ini redaksi, tanpa melibatkan warga. Kondisi ini memungkinkan terjadinya pemilahan, penonjolan, atau penyembunyian fakta-fakta sebuah peristiwa yang diproduksi. Warga dalam skema kerja produksi konten (berita) menjadi pasif sehingga apapun produk berita yang dihasilkan oleh redaksi itulah yang dikonsumsi oleh warga. Hal ini sejalan dengan penegasan berikut,

Issues surrounding audiences tend to focus on the impact of media practices upon people $\mathcal{E}$ perceptions; how audiences shape media practices; how media practices function in the commodification of knowledge, epistemology, and communication more generally; and how the work of audiences is appropriated and sold by media corporations (Phil Graham dalam Albarran, 2006:494)

Sementaraitu,kehadirancitizenjournalism di internet tidak hanya sebagai penanda bagaimana teknologi mentransformasi pola konsumsi informasi dari media tradisional ke media baru, tetapi juga bagaimana internet mempengaruhi mekanisme produksi, penyebaran, pertukaran nilai, dan konsumsi informasi yang selama ini terpusat pada media tradisional. Karakteristik interaksi yang dimiliki internet memungkinkan 
proses komunikasi yang terjadi tidak bersifat satu arah selayaknya yang terjadi di media tradisional, bahkan menjadi lebih interaktif melalui media baru.Selanjutnya, era teknologi digital dan teknologi komunikasi telah mengubah arah komunikasi yang selama ini menganut pola broadcast. Jika model broadcast adalah komunikai satu arah, maka dengan kehadiran teknologi komunikasi bisa menjadi dua arah bahkan lebih atraktif. Komunikasi terjadi tidak lagi memakai pola dari sumber yang satu menyebar ke banyak (broadcast), berpusat, khalayak bersifat pasif, dan penerima berada dalam posisi terisolasi (Levy, 2001:223), melainkan lebih dinamis, tidak tersentral, dan sampai pada melibatkan khalayak.

\section{PEMBAHASAN \\ Ekonomi-Politik Media Baru}

Dalam perspektif cultural studies, internet merupakan ruang di mana kultur yang terjadi diproduksi, didistribusikan, dan dikonsumsi. Sebagaimana sifat dasar perspektif ini yang mengaburkan kelaskelas sebagai sebuah strata yang ada di tengah masyarakat, cultural studies memberikan semacam perlawanan dari sebuah kemapanan strukturasi kelas sosial. Gerakan-gerakan sosial seperti feminisme menandakan bahwa sebuah kultur tidak hanya diciptakan oleh kelas tertentu, dalam teori Marx klasik misalnya oleh mereka yang menguasai alat-alat produksi dan memiliki modal, namun bisa dihasilkan oleh masyarakat bahkan individu yang merupakan agen-agen sosial (Mosco, 1996: 251). Jika memakai terminologi ekonomipolitik, maka kultur merupakan komoditas yang diproduksi. Artinya, pendekatan cultural studies dalam melihat budaya siber yang ada di internet memberikan arah untuk melihat bagaimana proses komodifikasi itu terjadi di ruang virtual; dengan tentu saja mengabaikan kajiannya berdasarkan perdedaan kelas hingga hubungan pekerjapemodal sebagaimana hal ini menjadi sentral awal diskursus tentang ekonomipolitik (Mosco, 1996: 252). Jika ekonomi- politik mengawali pembahasannya melalui "macrosocial organization of power" atau organisasi kekuasaan, maka cultural studies mendekatinya melalui "local organization of power" di mana kekuasaan itu berada di dalam diri subyek atau individu itu sendiri (inter-subjective). Bagi Mosco, fokus dari cultural studies terletak pada teks sebagai salah satu titik awal untuk melihat bagaimana fenomena sosial yang terjadi.

McQuail (2001: 124) menegaskan bahwa ada hubungan antara ekonomi-politik dan budaya di media. Aspek ekonomi-politik memainkan peran dari pengaturan produksi budaya yang terjadi di industri media massa sebagai 'industri dengan kesadaran'. Media pada dasarnya merupakan institusi yang disetir oleh logika ekonomi sampai pada perubahan budaya. Aspek penting dalam pemikiran McQuail ini adalah komodifikasi budaya dalam bentuk 'perangkat lunak' yang diproduksi oleh dan untuk 'perangkat keras' komunikasi yang keduanya dijual dalam pasar yang lebih luas.

Teoretisi cyberculture seperti Manuel Castells (2000: 18) menegaskan bahwa perkembangan teknologi internet pada dasarnya melahirkan apa yang disebut sebagai "informational capitalism". Bahwa teknologi dan entitas yang berada di dalamnya seperti produsen (perangkat keras maupun lunak), distributor, pengiklan, maupun pengguna merupakan model ekonomi baru yang melandaskan produk atau komoditasnya pada informasi. Lebih jauh Manuel Castells (2000: 9) menegaskan,

We are still in a capitalist mode of production, in terms of the relations between capital, property ownership and labour (even if, as we shall see, he argues that the social structure, i.e. class, has fundamentally changed). Following his old mentor, Alain Touraine, he specifies a mode of development as 'the technological arrangements through which humans act upon matter (nature), upon themselves, and upon other humans' in order to generate wealth

The technological arrangements through which humans act upon matter (nature), upon themselves, and upon other humans' in order to generate wealth (Castells, 2000: 9). 
Perkembangan teknologi baru memberikan paradigma baru pula terhadap bentuk-bentuk ekonomi baru. Namun patut dicatat bahwa teknologi informasi tidaklah serta-merta mengubah kultur yang ada di tengah masyarakat dan jika ada perubahan kultur pun disebabkan oleh interaksi yang terjadi antara keduanya (Castells, 2010: 5). Teknologi informasi jika dipandang sebagai sebuah mesin memberikan kemudahan terhadap transformasi informasi itu sendiri menjadi produk (komoditi) dari sebuah proses produksi "the products of new information technology industries are information producing devices or information processing itself" (Castells, 1996:67). Informasi menjadi komoditas yang diperebutkan baik oleh pekerja, pemilik perusahaan, maupun melibatkan negara. Dengan kata lain, siapa yang bisa menguasai cum memanipulasi informasi, maka dianggap akan memenangi persaingan global sebagaimana yang disebut Castells sebagai "dot.com businesses". Juga, individu sebagai entitas secara otomatis memposisikan dan diposisikan sebagai pekerja yang telah terprogram atau "selfprogrammable".

Hal yang berbeda dikemukakan oleh McQuail (2011: 244-245). Ia menegaskan jika menilik dari sudut pandang ekonomi khalayak, memiliki karakteristik tersendiri yang berbeda dengan institusi ekonomi lainnya. Hal ini terjadi karena media dipengaruhi oleh ekonomi, politik serta teknologi yang memainkan peran dalam membentuk khalayak media. Karakter khalayak media, misalnya, seringkali tidak hanya muncul karena fungsi politik media dalam demokrasi, tetapi juga dari fakta bahwa informasi, budaya, dan gagasan yang ditawarkan media dianggap sebagai kepemilikan kolektif.

Individu sebagai sebuah entitas di media internet juga menjelma tidak hanya sebagai konsumen, tetapi juga sebagai produsen. Bahkan, dalam beberapa kasus entitas tersebut sekaligus menjadi konsumen/ produsen. Misalnya, ketika individu membuka situs citizen journalism di internet, maka saat itu pula kondisi konsumen/ produsen terjadi. Individu menjadikonsumen saat ia menggunakan media citizen journalism atau membaca konten. Berbarengan dengan itu, saat individu menulis serta mempublikasikan konten di media citizen journalism, pada dasarnya individu tersebut tengah memproduksi informasi sebagai sebuah komoditas. Demikian pula, entitas yang ada di internet merupakan bagian dari proses produksi dan juga sebagai sumber dari apa yang diproduksi tersebut. Oleh karena itu, pencitraan diri di dunia virtual merupakan upaya yang dilakukan individu untuk mendapatkan balasan (reward), baik secara ekonomi maupun politik.

Fenomena di atas ditegaskan lagi oleh Joseph E. Davis (2003) yang menawarkan konsep "commodification of self". Pencitraan diri pengguna dipandang sebagai upaya komodifikasi diri yang tidak hanya terpaku pada sesuatu (barang/benda) yang bisa dijual maupun dibeli, tetapi juga pada kehidupan pribadi. Komoditas terhadap diri disebut Davis sebagai "personal branding" yang merupakan upaya pemanfaatan pencitraan diri maupun anggapan mengenai diri untuk kepentingan ekonomi. "[a] strategy of cultivating name and image of ourselves that we manipulate for economic gain" (Davis, 2003: 41).

Pemanfaatan media baru oleh khalayak dimungkinkan terjadi karena posisinya tidak lagi sebagai bagian massa yang bisa dikontrol (McQuail, 2011:150). Bahkan, keragaman penggunaan dan pengawasan yang terjadi di media baru merupakan hambatan tersendiri dalam mencirikan masa depan media baru itu sendiri. Media baru menciptakan banyak varian dan tidak ada satu pun yang mendominasi selayaknya yang terjadi di media tradisional. Inilah yang disebut sebagai 'batasan antara penerbit, produsen, distributor, konsumen, dan pengamat konten semakin kabur' (Rice, 1999: 29 dalam McQuail, 2011: 153). Malah, bagi McQuail, media baru dan budaya yang muncul di dalamnya telah mengaburkan 'lembaga media'. Artinya, media baru memberikan kebebasan kepada khalayak (user) untuk mempublikasikan 
konten tanpa perlu pengawasan yang ketat. Implikasi dari kebebasan tersebut, memakai perspektif ekonomi-politik, bisa saja media baru dimanfaatkan oleh khalayak untuk mempublikasikan konten (komoditas) demi kepentingan materi (value).

Terkait dengan media baru dan komoditas, dalam pandangan Miller (2010) media baru memberikan sarana bagi aktivitas menulis tentang diri di jurnal elektronik. Blogging pada dasarnya merupakan kegiatan menampilkan citra diri atau memproduksi konten (informasi) yang terpusat pada diri; meminjam istilah yang dipopulerkan Giddens, Miller (2010: 535) menyebutnya sebagai konsep "individualization". Secara umum, bisa dikatakan, terminologi "individualization" disandarkan pada sebuah proses di mana komunitas dan hubungan personal di dalamnya, bentuk-bentuk kelompok sosial dan komitmen terhadap kelompok tersebut semakin berkurang karena faktor-faktor seperti sejarah, tempat, dan atau tradisi. Pada saat itulah individu membebaskan dirinya dari ruang, tradisi, pengaruh globalisasi, maupun sejarah dan pada akhirnya individu akan memposisikan diri sesuai dengan konteks kebutuhan saat itu, membentuk diri serta mengkonstruksi diri sebebas-bebasnya. Dalam pandangan Giddens, sebagaimana dikutip Willey, bahwa hubungan yang murni terbangun secara sadar dan sukarela. Selanjutnya, hubungan tersebut akan semakin erat apabila di antara individu, pancaran identitas diri di antara individu tersebut merefleksikan hal yang sama, saling menyadari adanya kebutuhan, dilandasi rasa kepercayaan, serta adanya pengungkapan diri (self-disclosure) untuk meraih kepercayaan.

Inilah yang menjadi perhatian Miller tentang informasi diri yang didistribusikan melalui media baru dan aktivitas blogging. Konten yang dihasilkan oleh individu pada dasarnya memuat informasi tentang dirinya dan informasi tersebut menjelma sebagai komoditas yang digunakan untuk membangun dan merawat hubungan dengan individu lain. Konsep produksi informasi diri tersebut bagi
Miller merupakan salah satu karakteristik dari entitas dalam jejaring, sebagaimana dijelaskan oleh Castells $(2000,2006)$ dan menjadi semacam "database", dalam pandangan Manovich (2001), yang bisa dikonsumsi oleh entitas lainnya. Miller menegaskan,

Blogging, for the most part, is based on the notion that information is a commodity that is used to build and maintain relationships. In persolan journal blogs, it is personal information, creatde through realationships of mutual self-disclosure, which attains a commodified status. In the case of other types of blogging (political, news, technological and the like), substantive information is commodity. In both thee case, this exchange is based on the logic of the 'pure' relationship: an exchange of substantive information achieved through dialogue. This exchange creates tenuous individually-oriented self-defined communities or networks, which revolve around shared interests and dialogic exchange related to those interests (Miller, 2010: 536).

Inilah alasannya, mengapa di internet individu menjadi entitas yang selain mengkonsumsi juga menghasilkan produk. Sebagaimana telah diterangkan oleh Castells sifat internet yang menghubungkan antarentitas melalui perantaraan perangkat komputer pada akhirnya menciptakan perangkat tersebut sebagai pabrik dalam memproduksi produk informasi; proses ini disebut Boellstorff (2008: 206) sebagai "creationist capitalism", informasi atau konten yang ada di dunia virtual pada dasarnya merupakan produk kreatif dari entitas itu sendiri.

\section{Pemanfaatan Ruang Citizen Journalism}

Meskipun Kompasiana (dipakai penulis sebagai instrumen untuk melihat kasus) merupakan media citizen journalism yang dibangun oleh institusi media Kelompok Kompas Gramedia dan menjadikan warga, dalam pandangan Mosco, sebagai komoditas dan atau sebagai pekerja yang menghasilkan dan mengiklankan komoditas, namun warga tetap memiliki posisi untuk melakukan negoisasi. Negoisasi tersebut terjadi dengan pemanfaatan media citizen journalism oleh 
warga. Setidaknya, menurut hasil penelitian, penulis melihat ada tiga bentuk pemanfaatan media Kompasiana, yaitu, pertama, pemanfaatan akun dan informasi pemilik akun. Dari hasil penelitian yang dilakukan, terlihat bahwa pemanfaatan media citizen journalism dengan mengambil instrumen di Kompasiana bisa dilakukan sejak pertama kali pengguna (user) mendaftarkan diri atau membuat akun di Kompasiana. Perangkat yang disediakan oleh Kompasiana bisa dimanfaatkan oleh siapa saja atau institusi apa saja berdasarkan motif-motif tertentu. Tidak adanya verifikasi merupakan salah satu alasan bagaimana mudahnya sebuah akun diciptakan dan dimanipulasi di ruang citizen journalism Kompasiana. Namun, perlu ada catatan di sini, bahwa verifikasi yang dilakukan oleh admin Kompasiana dilakukan hanya terhadap akun dengan identitas dari tokoh publik atau tokoh terkenal, seperti pada akun Marzuki Alie atau penulis Pipiet Senja.

Kedua, pemanfaatan konten dan kolom komentar (lihat Gambar 1). Sebuah konten yang dipublikasikan dalam kolom atau ruang Kompasiana juga seolah-olah dibebaskan. Pihak Kompasiana hanya mengikat pengguna dengan aturan-aturan yang dipublikasikan dalam "Ketentuan Jurnalisme Warga" (diakses dari http://www.kompasiana. com/term pada 18 Januari 2012). Dalam penjelasan umum tentang media Kompasiana, memposisikan diri sebagai media warga atau citizen media dimana setiap warga dapat menginformasikan peristiwa di media ini.

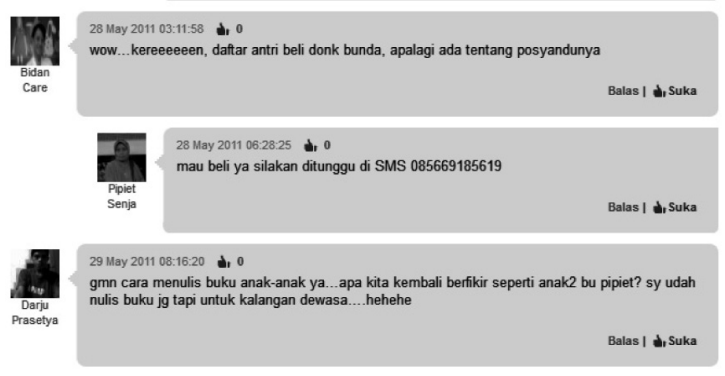

\section{Gambar 1}

Pemanfaatan Ruang Komentar untuk Promosi sumber: http:/ / media.kompasiana.com/ buku/2011/05/25/serial-balita-muslimpersembahanku-untuk-balita-sejagat/diakses pada 13 Januari 2012
Sebagai media citizen journalism yang dikelola oleh institusi media tradisional, Kompasiana pada praktiknya memiliki admin. Tugas admin berbeda dengan editor atau redaktur di redaksi media. Meskipun dalam kondisi tertentu, seorang admin di Kompasiana bisa merangkap sebagai redaktur-terutama dalam kanal liputan khusus (lipsus) di Kompasiana yang memuat kejadian-kejadian tertentu seperti tsunami di Jepang-namun ia hanya berfungsi memastikan bahwa tidak ada konten yang dipublikasikan di Kompasiana menyinggung persoalan SARA dan aturan-aturan yang telah ditentukan lainnya. Dalam kondisi tertentu, admin bisa menghapus sebuah konten yang dipublikasikan oleh warga. Admin pula yang akan memilih mana tulisan warga yang menjadi headline atau konten utama dalam halaman muka Kompasiana; kehadiran sisipan Kompasiana yakni Freez di Kompas setiap hari Kamis juga membebankan admin untuk menyeleksi dan menyunting konten apa yang akan dipublikasikan. Terkait dengan hal tersebut, Iskandar menyatakan,

...Admin Kompasiana setiap hari mengelola konten yang masuk menjadi tulisan utama (headline) ataupun tulisan pilihan (highlight). Ini dilakukan untuk meningkatkan jumlah pembaca dan mengubah citra blog yang selama ini dianggap main-main dan berisi konten-konten sampah. Sehingga yang tersaji di Kompasiana adalah konten-konten warga pilihan yang layak dibaca banyak orang (Iskandar, 2011:19).

Ketiga, pemanfaatanoffline dari Kompasiana. Selain proses pemanfaatan di ruang citizen journalism secara online, pemanfaatan oleh warga juga dilakukan secara offline. Pengguna Hazmi Srondol (http://www.kompasiana. com/srondol) merupakan perwakilan pengguna yang diangkat penulis untuk menunjukkan bahwa ada pemanfaatan media citizen journalism di dunia nyata. Publikasi buku yang berisi konten-konten yang di ruang Kompasiana adalah contoh dari upaya negosiasi warga terhadap media Kompasiana. Meskipun dalam penerbitan buku tersebut dicantumkan logo Kompasiana dan kenyataan ini bisa dipakai 
untuk membuktikan bahwa komodifikasi dari aspek perusahaan yang menyediakan Kompasiana semakin lebar melalui media buku, namun warga juga mendapatkan keuntungan dengan mencantumkan logo Kompasiana tersebut. Keuntungan tersebut, misalnya, liputan oleh media yang ada di Kelompok Kompas Gramedia - seperti terjadi pada Wisnu Nugroho-atau lenturnya syarat pelarangan iklan di konten Kompasiana-seperti promosi buku Hazmi Srondol - karena yang diiklankan adalah seolah-olah produk atau yang di-endors oleh Kompasiana.

Penulis melihat bahwa ada proses negoisasi di sini; bahwa Kompasiana dan juga pengiklan memanfaatkan pengguna untuk memproduksi konten di ruang Kompasiana. Sebaliknya, pengguna juga memanfaatkan ruang sampai pencitraan media citizen journalism. Juga, sebagai contoh untuk kasus buku Hazmi Srondol, upaya pemanfaatan tersebut dilakukan dengan jaringan bisnis yang dimiliki oleh Kelompok Kompas Gramedia, yaitu dengan memanfaatkan perusahaan distribusi buku untuk disebar ke toko-toko buku milik Kelompok Kompas Gramedia.

Tiga bentuk pemanfaatan warga dalam media citizen journalism seperti yang terjadi di Kompasiana ini menunjukkan bahwa warga tidak hanya berposisi pasif dan sebagai pekerja dalam menghasilkan konten, tetapi juga warga bisa memanfaatkan ruang citizen journalism berdasarkan motif-motif tertentu.

\section{Negoisasi Warga-Pasar dalam Ruang Citizen Journalism}

Kehadiran Kompasiana sebagai media citizen journalism memberikan pengaruh pada iklan dan penjualan (produk) media, baik itu edisi terbitan maupun program, merupakan sumber pendanaan yang diperoleh media. Selama ini, semakin banyak penonton yang menyaksikan, membaca, atau mendengar sebuah program, maka akan semakin populer program cum media tersebut di tengah warga. Efek dari kepopuleran tersebut pun akan menarik minat korporasi untuk beriklan.

Dalam proses produksi-distribusi konten menurut Albarran (1996: 14-15) institusi media setidaknya harus mempertimbangkan beberapa hal. Pertama, apa produk yang akan dihasilkan. Pertimbangan ini menjadi penting karena produk, sebagaimana industri ekonomi lainnya merupakan sesuatu yang akan diperdagangkan. Misalnya pada media cetak, beragam peristiwa yang ada di lapangan tidak bisa serta-merta diproduksi menjadi sebuah berita. Institusi media harus melakukan pemilihan dan seleksi isu apa saja yang akan diberitakan di media sesuai dengan sasaran konsumen yang akan dituju.

Kedua, ketika konten telah dipilih, maka pertimbangan selanjutnya bagaimana konten tersebut diproduksi. Pertimbangan ini melibatkan berapa banyak sumber daya manusia yang dilibatkan dalam sebuah proses produksi konten. Sebuah berita yang tayang di satu stasiun televisi, misalnya satu berita yang dibacakan di sela-sela program acara lain atau dikenal dengan sebutan breaking news dan berdurasi tak lebih dari satu hingga tiga menit, tentu saja melibatkan tidak hanya pembaca berita yang tampak di layar televisi, tetapi juga melibatkan kameraman, penata cahaya, tata rias, penulis berita, hingga reporter dan camera person di lapangan. Faktor tenaga kerja inilah yang menurut Dunnett menjadi pengeluaran perusahaan yang termahal.

Ketiga, ketika produk telah dipilih dan telah dihasilkan, maka pertimbangan selanjutnya adalah siapa yang akan mengkonsumsi produk tersebut. Konsumenlah yang akan membayar produk yang mereka pilih untuk disaksikan, misalnya dalam penjualan TV berlangganan, konsumen akan membayar sesuai dengan program yang dipilih. Sementara itu, pada televisi umum yang bersifat gratis, maka media mendapatkan dari berapa banyak program tersebut disaksikan oleh penonton (rating dan share). Semakin banyak jumlah penonton, maka akan semakin tinggi tingkat kepopuleran (rating) program tersebut; tentu saja akan menarik minat perusahaan atau biro-biro untuk memasang iklan di program tersebut, dengan harapan ketika menyaksikan program yang ditayang di televisi para penonton juga menyaksikan iklan yang tayang dan memutuskan untuk membeli produk yang diiklankan. 
Kehadiran beragam media pada dasarnya memberikan peluang bagi warga untuk menentukan media apa yang akan diakses. Sebuah berita yang terjadi saat ini tidak hanya bisa disaksikan melalui siaran televisi, tetapi juga bisa didengar melalui radio, dibaca di koran atau majalah, dan juga bisa diakes melalui media internet. Meminjam teori supply-demand, Albarran menegaskan bahwa semakin murah dan mudah warga untuk mengkonsumsi konten, maka semakin diminati media yang memproduksi konten tersebut (Albarran, 1996: 17-20).

Pernyataan-pernyataan yang disajikan berikut ini membuktikan bahwa warga menjadi faktor kunci dalam perolehan iklan di perusahaan media tradisional. Namun, penulis melalui penelitian yang dilakukan menemukan bahwa media citizen journalism bisa juga digunakan oleh warga untuk beriklan (lihat Gambar 2).

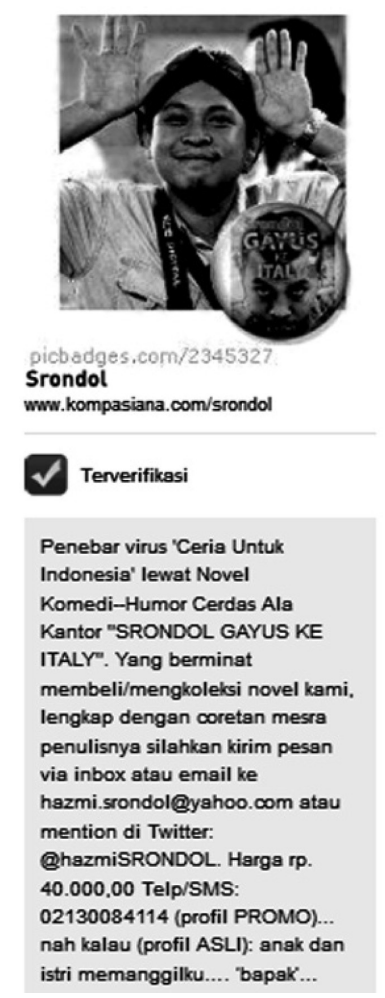

Gambar 2

Deskripsi Diri Akun Srondol di Kompasiana

Sumber: http:/ / www.kompasiana.com/srondol diakses pada 22 Desember 2011
Meski Kompasiana sebagai media jurnalisme warga yang dibentuk oleh perusahaan media tradisional dan dalam ketentuan layanannya tidak memperkenankan warga yang memiliki akun untuk beriklan, namun dengan menyamarkan konten yang dipublikasikan atau bisa juga melalui diskusi di ruang komentar memberikan peluang bagi warga untuk menyisipi iklan. Pemanfaatan ruang konten, pemanfaatan foto profil (avatar), pemanfaatan deskripsi pemilik akun di Kompasiana, dan pemanfaatan ruang komentar (untuk kasis ini lihat akun http:/ / www.kompasiana.com/nuansacendekia dan http://www.kompasiana.com/ www. pipitsenja.multiply.com) menandakan bagaimana warga menggunakan media citizen journalism untuk beriklan. Hal ini terungkap dalam wawancara dengan Pipit Senja yang mengatakan,

Dipromosikan sih tidak, karena Kompasiana melarang kita tidak memposting yang berbau iklan. Hanya saya pajang nukilannya, kemudian diam-diam nanti jika ada yang bertanya; diamanakah bisa pesan, ya saya jawab bisa pesan langsung ke nomer saya (Wawancara dengan Pipiet Senja, 16 Desember 2011).

Meskipun pemasukan iklan yang diperoleh warga hanya bersifat sementara dan untuk kasus-kasus tertentu saja dan tidak sebanyak dan sesering yang diperoleh pengelola media Kompasiana, namun kasus tersebut menandakan bahwa ada semacam ancaman bagi media tradisional terhadap pemasukan iklan yang mulai melirik media citizen journalism. Di sinilah penulis melihat bahwa kekuatan warga dalam citizen journalism tidak hanya menegosiasikan produksi informasi dan siapa yang berhak mendistribusikannya, tetapi juga menegosiasikan publikasi iklan. Aturan yang diterapkan oleh Kompasiana ternyata tidak serta-merta mengikat warga yang memiliki akun. Warga tetap saja bisa beriklan di Kompasiana 


\section{SIMPULAN}

Kemajuan teknologi internet, ditambah dengan karakteristik media baru menyebabkan fenomena citizen journalism berkembang semakin pesat. Fenomena ini tidak hanya dimanfaatkan oleh warga untuk memproduksi sekaligus mengkonsumsi (produsage) informasi, tetapi juga mendapat perhatian media tradisional. Meminjam perspektif yang digunakan oleh Deuze (2009: 255) dalam artikelnya "The Future of Citizen Journalism", maraknya fenomena citizen journalism bisa didekati melalui perspektif ekonomi-industri, perspektif khalayak, dan persepektif kultur. Ketiga perspektif ini disebut Deuze sebagai "a framework of convergence culture".

Melalui perspektif ekonomi-industri, fenomena citizen journalism merupakan gerakan penyebaran informasi yang dilakukan oleh warga serta peluang bisnis media dengan atau tanpa mengeluarkan uang sama sekali karena konten sepenuhnya diisi oleh warga (citizen-volunteers). Tentu saja, peluang ini memberikan keuntungan bagi perusahaan media tradisional yang tidak bisa menjangkau area liputan yang sangat luas maupun momentum terhadap sebuah peristiwa.

Di tengah maraknya bermunculan media-media baru, tentu saja usaha untuk mendapatkan momentum sebuah peristiwa menjadi usaha yang dibutuhkan biaya dan sumber daya manusia (SDM) yang tidak sedikit. Indonesia, misalnya, dengan jumlah kota kecamatan yang cukup banyak tidak akan mampu dipenuhi oleh perusahaan media untuk menyediakan SDM jurnalis, dengan gaji, tunjangan, serta fasilitas lainnya. Namun, kehadiran warga secara sukarela menjadikan fenomena citizen journalism sebagai pekerja lepas yang tidak dibayar untuk memasok berita terkini kepada redaksi media.

Dalam perspektif khalayak, citizen journalism tidak hanya memberikan peluang pelibatan warga dalam memproduksi berita, melainkan juga memberikan alternatif bagi sumber informasi yang selama ini dikuasai oleh perusahaan media tradisional. Khalayak menjadi sumber informasi yang bisa memasok konten tanpa adanya penyuntingan layaknya mekanisme redaksional, sehingga akan lebih memberikan sentuhan asli dalam penyampaian opini atau kasus menurut kacamata dan juga ekspresi khalayak itu sendiri. Namun demikian, efek dari keterlibatan khalayak sebagai pemasok informasi dalam citizen journalism juga memberikan peluang bagi warga untuk memanfaatkan media citizen journalism untuk kepentingan pribadi, misalnya untuk motif ekonomi. Konteks masalah pribadi yang dipublikasikan di konten media citizen journalism, bisa dikategorikan upaya khalayak untuk mendapatkan keuntungan baik berupa materi maupun non-materi. Kebebasan dalam mengkonstruk (identitas) akun dan mempublikasikan konten di media citizen journalism merupakan alasan yang bisa digunakan oleh khalayak yang ingin memanfaatkan media citizen journalism.

Perspektif terakhir, yakni fenomena citizen journalism merupakan fenomena yang membawa perubahan pada kultur. Mulai dari kultur dalam mengakses media informasi, kultur berinteraksi serta pengungkapan diri atau pencitraan diri, dan bagaimana kultur profesional jurnalis cum perusahaan media dalam memposisikan khalayak. Selama ini, khalayak merupakan sasaran terpaan informasi media dan bersifat pasif, kehadiran media citizen journalism membawa pada perubahan yang bisa dikatakan cukup drastis dalam memandang posisi khalayak. Inilah yang disebut Deuze bahwa dalam era perkembangan citizen journalism diperlukan kerjasama antara profesional media dan khalayak dalam menjalani perubahan kultur, terutama kultur di dalam bidang jurnalisme.

Warga tidak lagi menjadi entitas pasif yang hanya menerima terpaan informasi sebagaimana yang diproduksi oleh media. Informasi menjadi milik bersama antara warga, pekerja media, perusahaan media hingga pemerintah. Setiap komponen memiliki porsi dan posisi sama dalam memproduksi informasi sesuai dengan 
sudut pandang dan kepentingan masingmasing. Jika pertanyaan yang muncul adalah mungkinkah warga bisa menghasilkan produk informasi yakni berita yang seakurat mungkin dengan menjunjung kode etik sebagaimana jurnalis yang terikat dengan Kode Etik Jurnalistik? Maka fenomena citizen journalism dan warga yang terlibat di dalamnya menunjukkan betapa urusan "profesional" tidak lagi menjadi milik pekerja jurnalis yang bekerja di perusahaan media semata. Warga tanpa mengenal tingkatan atau jenjang pendidikan menjadi entitas yang bisa terlibat dalam citizen journalism. Ditambah lagi sumber-sumber internet memberikan beragam pengetahuan yang bisa meningkatkan kemampuan teknis maupun standar keprofesionalan warga layaknya jurnalis profesional.

Posisi warga yang kini memegang kendali terhadap produksi dan distribusi informasi pada dasarnya membawa efek tersendiri.Setidaknyadalamparadigmakritis, beberapa kasus yang dijadikan contoh dalam tulisan ini jelas dan tegas mempertanyakan tesis Jesse Hicks dan Curt Chandler tersebut. Terhadap pernyataan "not for monetary reward, but because they have a particular interest in a topic" bahwa hasil penelitian penulis dengan tegas menggambarkan bagaimana media citizen journalism bisa dimanfaatkan untuk kepentingan ekonomi dan pencitraan diri. Meski dalam penulisan ini tidak bermaksud melakukan generalisasi terhadap semua pengguna (kompasianer) bahwa mereka memiliki motif ekonomi-politik sebagai kasus-kasus yang penulis temukan, namun hasil penelitian yang dilakukan penulis merupakan bukti bahwa tesis Jesse Hicks dan Curt Chandler patut diragukan; dan bahkan untuk beberapa kasus membantah tesis tersebut.

Selanjutnya, komodifikasi terhadap media citizen journalism yang dilakukan oleh warga merupakan fenomena tandingan komodifikasiyangdilakukanolehperusahaan media tradisional. Ini menunjukkan adanya gejala tarik-menarik dalam ruang (pasar) citizenjournalism. Tidakselamanyajuga warga bersikap pasif terhadap terpaan media dan dijadikan komoditas oleh perusahaan media tradisional maupun pengiklan, melainkan warga juga bisa melakukan komodifikasi sesuai dengan capaian apa yang ingin diraih oleh mereka.

\section{DAFTAR PUSTAKA}

Allan, Stuart and Thorsen, Einar (ed.), 2009, Citizen Journalism. A Global Perspectives, New York: Peter Lang.

Aranguren, J.L, 1967, Human Communication. New York: McGraw Hill Book Co.

Atton, Chris, 2009, Alternative and Citizen Journalism dalam Karin WahlJorgensen and Thomas Hanitzsch (ed.). The Handbook of Journalism Studies. New York: Routledge.

Banda, F., 2010, Citizen Journalism $\mathcal{E}$ Democracy in Africa. South Africa: Highway Africa.

Albarran, A. B, 1996, Media Economics. Iowa: Iowa State University Press.

Barna, K; 2009, Citizen Participation and Online Media: Crossroads of Technology and News. Departement of Polictical Science, Central European University di Budapest, Hungaria.

Bell, D; 2007, Cyberculture Theorists, Manuel Castells and Donna Haraway. London and New York: Routledge. 2001, An Introduction to Cybercultures. London and New York: Routledge.

Bruns, A; 2010b, From Reader to Writer: Citizen Journalism as News Produsage dalam Jeremy Hunsinger, Lisbeth Klastrup, and Matthew Allen, Internet Research Handbook, Dordrecht. NL: Springer. Hal. 119-134. , 2009a, Citizen Journalism and Everyday Life: A Case Study of Germany's myHeimat.de dalam Bob Franklin and Matt Carlson, Journalists, Sources, and Credibility: New Perspectives. London: Routledge. 
Bruns, A. W, Jason and Saunders, Barry, 2009b, Citizen Journalism as Social Networking: Reporting the 2007 Australian Federal Election dalam Stuart Allan \& Einar Thorsen (ed.). Citizen Journalism: Global Perspectives. New York: Peter Lang.

Bruns, A, 2008a, News Blogs and Citizen Journalism dalam Kiran Prasad (ed.). e-Journalism: New Directions in Electronic News Media. New Delhi: BR Publishing.

2008b, Gatewatching, Gatecrashing: Futures for Tactical News Media dalam Megan Boler (ed.), Digital Media and Democracy: Tactics in Hard Times. Cambridge, Mass.: MIT P.

Bruns, A. Wilson, Jason A. E Saunders, Barry J, 2008c, Building Spaces for Hyperlocal Citizen Journalism, prosiding seminar Association of Internet Researchers 2008 : Internet Research 9.0: Rethinking Community, Rethinking Place, October 15, 2008 - October 18, 2008, Copenhagen, Denmark.

Bruns, Axel, 2005, Gatewatching: Collaborative Online News Production. New York: Peter Lang.

Castells, M; 1996, The Information Age: Economy, Society \& Culture, Vol.1: The Rise of The Network Society. Oxford: Blackwell Publishing Ltd.

Castells, M; 1997, The Information Age: Economy, Society \& Culture, Vol.2: The Power of Identity. Oxford: Blackwell Publishing Ltd.

Castells, M; 1998. The Information Age: Economy, Society \& Culture, Vol.3: The End of the Millennium. Oxford: Blackwell Publishing Ltd.

Castells, M; 2000, "Materials for an Exploratory Theory of the Network Society". British Journal of Sociology 51(1): 5 - 24.
Castells, M; 2001, The Internet Galaxy. Oxford: Oxford University Press.

Castell, M; 2010, Informatian Age; Economy, Society, and Culture. Oxford: Blackwell Publishing Ltd.

Deuze, M, 2009, The Future of Citizen Journalism dalam Allan, Stuart and Thorsen, Einar (eds.). Citizen Journalism, A Global Perspectives. New York: Peter Lang.

Deuze, M and B, Axel and Neuberger, Christoph, 2007, "Preparing for an Age of Participatory News" dalam jurnal Journalism Practice 1(3), hal. 322-338.

Dyer-Witheford, N, 2010, "Digital Labour, Species-Becoming and the Global Worker", dalam Jurnal Ephemera, Vol. 10, No. 3/4, hal. 484-503.

Flew, Terry and Wilson, Jason A, 2008, "Citizen journalism and Political Participation: the Youdecide Project and the 2007 Australian Federal Election", dalam Australian Journal of Communication, 35(2)., hal. 17-39.

Friedland, Lewis and Nakho Kim, 2009, Citizen Journalis dalam Christopher H. Sterling (ed.), Encyclopedia of Journalism. California: Sage Publications, Inc.

Hakken, David, 1999, Cyborgs@Cyberspace. New York-London: Oxford.

Hall, Stuart and Thorsen, Einar (eds.), 2009, Citizen Journalism, Global Perspectives. New York: Peter Lang.

Hesmondhalgh, D, 2010, "User-generated Content, Free Labour and the Cultural Industries", dalam Jurnal Ephemera, Vol. 10, No. 3/4, hal. 267-284.

Hicks, J, Probing Question: What is Citizen Journalism? dipublikasikan pada 13 Oktober 2009 <http://live.psu.edu/ story/42186> (diakses pada 10 Juni 2011). 
Levy, P, 2001, Cyberculture. Minnesota: University of Minnesota Press.

McQuail, D, 1987, Mass Communication Theory: An Introduction. Beverly Hills: Sage Publication.

, 2011, Komunikasi Massa. terj. Putri Iva Izzati. Jakarta: Penerbit Salemba Humanika.

Miller, V, 2010, New Media, Networking and Phatic Culture, dalam Nayar, Pramond K (.ed), The New Media and Cybercultures Anthology. Oxford: Willey-Blackwell. hal.534-543.

Mosco, V, 1996, The Political Economy of Communication. London: Sage Publication.
Nayar, P. K, 2010, The New Media and Cybercultures Anthology. Oxford: Wiley-Blackwell.

Rosenberry, J. and St. John III, Burton (eds.), 2010, Public Journalism 2.0, The Promise and Realty of a Citizen-engaged Press. New York: Routledge .

Smythe, D. W, 2006, On the Audience Commodity and its Work dalam Durham and Kellner (eds.), Media and Cultural Studies. Malden, MA:Blackwell Publishing .

Van Dijk, Jan, 2006, The Network Society: Social Aspects of New Media. London: Sage. 